\title{
Comparative Study of Dominant Routing Protocols in Ad Hoc Networks
}

\author{
Nagwan M. Abdel Samee \\ Assistant Professor, Network and Communication Systems Department, PNU, KSA \\ Assistant Professor, Computer Engineering Department, M.U.S.T, Egypt
}

\begin{abstract}
An ad hoc network is an autonomous self-organized wireless network. It consists of a collection of wireless nodes in which the communication paradigm is decentralized. The term "ad hoc" refers to the lack of any preexisting communication infrastructure such as routers in wired networks or access points in the traditional wireless networks. Instead, each node participates in routing by forwarding data for other nodes, so the determination of which nodes forward data is made dynamically on the basis of network connectivity. The ad hoc network is an autonomous system in which mobile hosts connected by wireless links are free to move randomly and often act as routers at the same time. As a result, the routing task in such type of networks introduces several types of challenges which were never apparent in the traditional infrastructure-based networks. The main objective of this study is to investigate the routing problem in wireless ad hoc networks. More specifically, the performance of the different ad hoc routing protocols which are dominantly adopted in such types of network environments will be examined. A simulation model with MAC and physical layer models, based on the simulation tool ns-2, was used in studying the behavior of two different protocols, namely, Ad Hoc On-Demand Distance Vector Routing (AODV), and DestinationSequenced Distance-Vector Routing (DSDV). Two performance metrics were used to establish a comparison between these routing algorithms: Average End-to-End Delay, and Packet Delivery Ratio. Simulation results showed that On-Demand routing protocol, AODV, provides a higher Packet Delivery Ratio. However, Table-Driven routing protocol, DSDV outperformed AODV in minimizing the Endto-End Delay.
\end{abstract}

\section{General Terms}

Wireless Networks, Ad Hoc Networks, Routing Protocols, Network Simulation

\section{Keywords}

Mobile Ad Hoc Networks Ad Hoc (MANET), On-Demand Distance Vector Routing (AODV), Destination-Sequenced Distance-Vector Routing (DSDV), End-to-End Delay, and Packet Delivery Ratio.

\section{INTRODUCTION}

Wireless networking is an evolving technology that allows various users to communicate regardless of their geographic position. The wireless natural environment paves the way to have a flexible mobility and does not pose any limit on user's localization. This mobility as well as the wireless mode of communication develops new characteristics that are specific to this natural environment, like the frequent disconnection, the connection flow and the limited power causes. On the other hand, it boasts a large flexibility of employment. Wireless networks can be classified in two types:
Infrastructure Networks, and Infrastructure less Networks "Ad hoc Networks". Infrastructure Networks is a based fixed infrastructure Networks like Celular Networks which is used in our daily life to get communication with others by mobile phones. It consists of fixed and wired gateways. The communication is done through a central node called Base station. However, Infrastructure less Networks such as Mobile Ad Hoc Network, MANETs, is not based on a fixed infrastructure, the network's structure changes dynamically and mobile nodes are responsible for routing and forwarding their packets to reach the desired destination[1]. Therefore, routing of packets in MANETs is a major challenge due to the complexity that face mobile nodes of keeping track of frequent and unpredictable topology changes, and available resources. Another important issue in MANETs is saving bandwidth. So, a special routing protocol that can adapt quickly to network changes with a minimum overhead of routing packets is needed for such type of wireless network. The main objective of this study is to get insight into one of the main challenges in Ad hoc networks, Routing of packets to reach its destination[2]. This is done by presenting an overview of a Mobile Ad hoc network as a type of Mobile Wireless network, and a simulation based study of dominant routing protocols for Ad hoc networks such as DSDV and AODV. This study should yield a decision about choosing an optimum routing protocol for Ad hoc networks from the proposed dominant list of routing protocol (DSDV, and AODV).

\section{BACKGROUND}

\subsection{Table-Driven versus On Demand Routing Protocols}

Table-driven routing protocols (Proactive) try to maintain consistent, up-to-date routing knowledge from each node to every other node in the network. These protocols need each node to maintain tables to store routing knowledge. Nodes reply to changes in network topology by propagating updates throughout the network in order to maintain a consistent network view. The areas in which they differ are the necessary number of routing-related tables, and the methods by which changes in network structure are broadcast. Proactive protocols are based on periodic exchange of control messages and routing tables [3]. A distinct approach from table-driven routing is source-initiated on-demand routing. This kind of routing creates routes only when yearned by the source node. When a node needs a path to a destination, it starts a path discovery process inside the mesh. This method is accomplished one time a path is found or all likely path permutations have been analyzed. One time a path has been established, it is maintained by a path upkeep method until either the place visited becomes inaccessible along every path from the source or until the path is no longer yearned. So the main task for Reactive Protocol is that find the paths to the destinations nodes[4]. 


\subsection{Distance Sequence Distance Vector routing (DSDV)}

DSDV described in [5] is a table-driven algorithm founded on the academic Bellman-Ford routing mechanism [6] to apply to mobile ad hoc networks. Transmission of packets between stations in the network is done using routing tables. As a distance- vector protocol, DSDV attach a routing table for each node. This table contain information about next-hop for each possible destination and each entry has a sequence number[7]. Routing information is broadcasted to all active nodes and updates must be transmitted immediately when any significant topology change is available [8].

\subsection{Ad hoc On Demand Distance Vector routing protocol (AODV)}

AODV is an improvement on DSDV because it typically minimizes the number of required broadcasts by creating routes on a demand basis, so it is considered as a type of Reactive routing protocols. In AODV routing, When a source node desires to send a message to some destination node and does not already have a valid route to that destination, it initiates a path discovery process to locate the other node. It broadcasts a route request (RREQ) packet to its neighbors, which then forward the request to their neighbors, and so on, until either the destination or an intermediate node with a "fresh enough" route to the destination is located. The rout is then unicasted to source node via a rout reply (RREP) message. Hello messages are special replies that are broadcasted periodically to the immediate neighbors. These messages are local advertisements for the continued presence of the node and to ensure the validity of routes at each node [7]. If a particular node stops sending hello messages, the neighbor can assume that the node has moved away and mark that link to the node as broken and notify the affected set of nodes by sending a link failure notification (a special RREP) to that set of nodes.

\section{RELATED WORK}

Routing in ad hoc networks requires different mechanisms when compared with packet switching network since a node in such network would act as both a host and router. So, many research have addressed the possibility of having an efficient Routing protocols for ad hoc Networks. Routing in ad hoc Network is a main challenge due to the node mobility, large number of nodes and limited power.

A comprehensive overview of Ad hoc network as a type of wireless network was provided in [1]. It explained the important role that mobile ad hoc networks has played in the evolution of future wireless technologies and reviewed the latest research activities in these areas of MANET_s characteristics, capabilities and applications.

Characteristics, and functionalities of Table-Driven and OnDemand routing protocol for Ad hoc networks were studied in [9]. That study stated that, Routing overhead was bigger in table driven than On-Demand routing protocols. However, the Route search overhead is big during the route discovery process in On-Demand routing protocols.

The influence of routing protocols on the performance of MANET was discussed in [10]. A simulation model with Media Access Control (MAC) and physical layer models were used to examine interlayer interactions and their performance implications. The results of this research showed that the performance of On-demand protocols, AODV, was more better than the traditional proactive routing protocol, DSDV.
A simulation based comparative analysis of DSDV and AODV was done in [11]. The packet delivery ratio and average end-to-end delay were the performance measures. The performance of AODV was better than DSDV when transmission power is increased. At higher transmission powers AODV routing load was increased.

\section{PERFORMANCE METRICS}

The goal of this research is to study and compare the performance of routing protocols through a set of simulation experiments. According to general idea described in RFC 2501 [11], Packet delivery ratio (PDR) and Average End-toEnd delay (AED) are the two important performance measures for best effort traffic. So, these metrics were used in evaluating the AODV and DSDV routing protocols. AED can be defined as the interval between the data packet generation time and the time when the destination received last bit. This metric exclusively deals with the network communication and speed effectiveness. Possibility of packet drop when speed is low because the delay is high and so needs the fault tolerance approach. However, PDR is ratio between the number of data packets delivered to the destinations and the number of data packets sent by the sources. This number presents the effectiveness of routing protocol in delivering packets from source to destination.

\section{SIMULATION EXPERIMENTS}

Four stages were followed to implement the proposed simulated experiments. A frame work of these stages is shown in Figure 1.

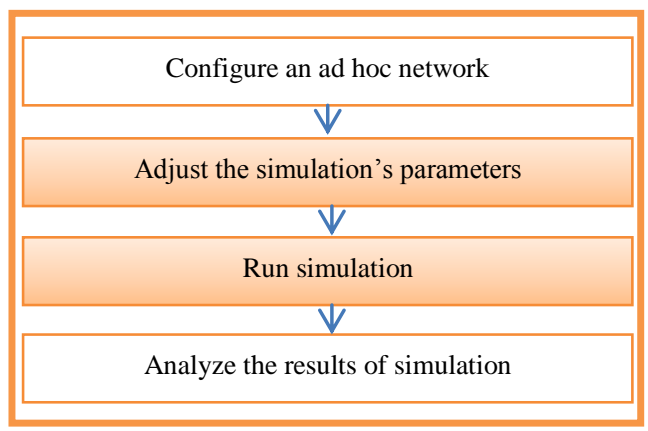

Figure 1: Steps of simulated experiments.

A proposed network containing fifty nodes (20 nodes act as servers and 30 node as destinations) was configured in NS2 simulator. These nodes were connected to each other by ad hoc network, moving about over a $500 \times 500 \mathrm{~m}$ flat space for 400 second of simulated time. Another parameters required for configuring a network including Channel type, Network Interface (netif), Propagation Model, Media Access Control (MAC), Link layer and Network layer are listed in table 1.

Table 1: NS2 parameters for network configuration

\begin{tabular}{|c|c|}
\hline Configure parameter & Definitions \\
\hline Channel type & WirelessChann. \\
\hline Network Interface (netif) & WirelessPhy. \\
\hline Propagation Model & $\begin{array}{c}\text { a composed component of network } \\
\text { interface, class Propagation and } \\
\text { MobileNode. }\end{array}$ \\
\hline
\end{tabular}




\begin{tabular}{|c|c|}
\hline $\begin{array}{c}\text { Media Access Control } \\
\text { (MAC) }\end{array}$ & $\begin{array}{c}\text { Mac802_11 inheriting from the } \\
\text { abstract class MAC. }\end{array}$ \\
\hline Link layer & $\begin{array}{c}\text { LL(inherits from LinkDelay).It has a } \\
\text { composed component ARP which } \\
\text { works as ARP procedure, mapping } \\
\text { the protocol address (such as IP } \\
\text { address) to Hardware address (such } \\
\text { as MAC address). }\end{array}$ \\
\hline Network layer & $\begin{array}{c}\text { routing agents with many variations } \\
\text { such as DSDV, AODV, etc. }\end{array}$ \\
\hline
\end{tabular}

\section{RESULTS}

Simulations were done for 24 scenarios with the routing protocols AODV and DSDV to get 47 trace files. After analyzing those 47 trace files with corresponding awk scripts, plotting of the graphs were done for the metrics with respect to the variables which were varied for performance evaluation. All the simulations are run for 400 seconds. With the variation of the mobility speed between 0 to $10 \mathrm{~m} / \mathrm{sec}$ and keeping number of connection equal to 20 , we got results shown in figure 2 for Packet Delivery Ratio and figure 3 for End to End delay respectively.

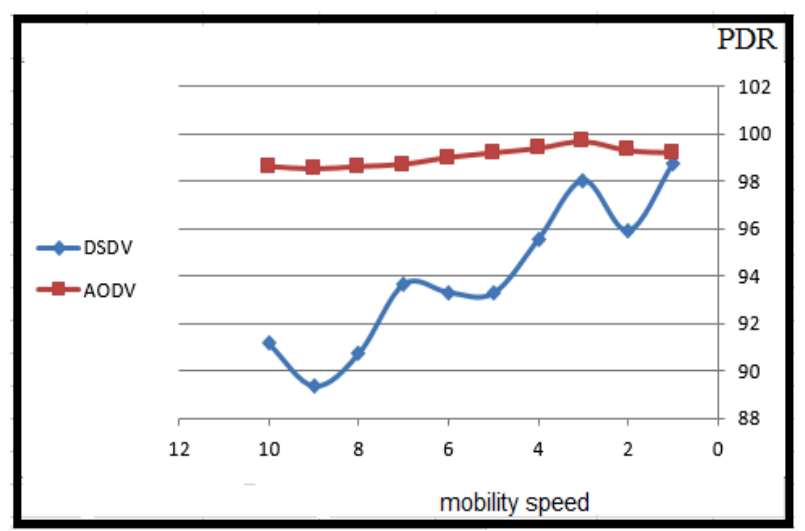

Figure 2: PDR versus mobility speed ranging from 1 to $10 \mathrm{~m} / \mathrm{sec}$.

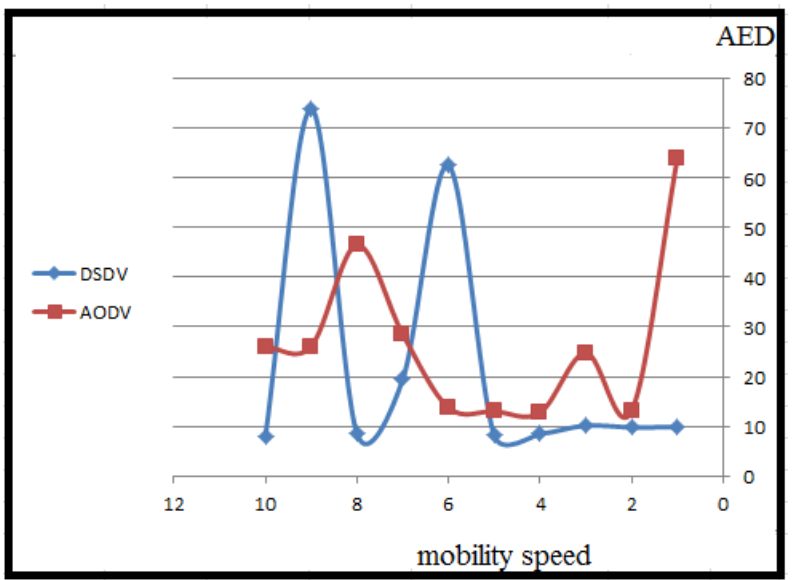

Figure 3: AED versus mobility speed from ranging from 1 to $10 \mathrm{~m} / \mathrm{sec}$.
With the variation of number of connection between $5,10,15,20$ and keeping the mobility speed equal to $10 \mathrm{~m} / \mathrm{sec}$, we got results in figure 4 for PDR and figure 5 for AED.

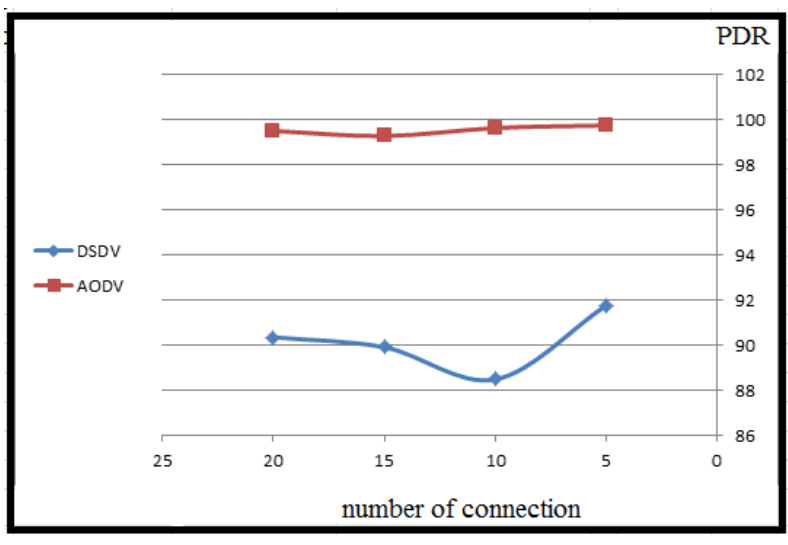

Figure 4: PDR versus different number of connections(5, 10,15 , and 2).

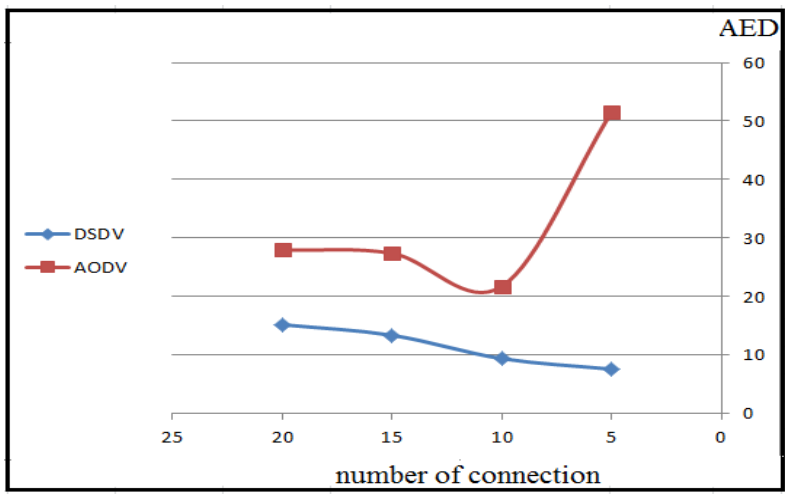

Figure 5: AED versus different number of connections (5, 10,15 , and 20).

With the variation of the mobility speed between 10 to 100 $\mathrm{m} / \mathrm{sec}$ and keeping number of connection equal to 20, we got results shown in figure 6 PDR and figure 7 for AED versus speed of mobility.

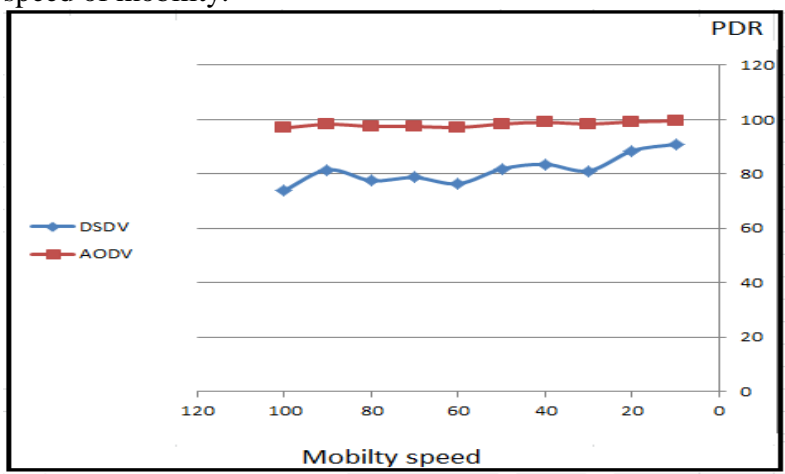

Figure 6: PDR versus mobility speed ranging from 10 to $100 \mathrm{~m} / \mathrm{sec}$. 


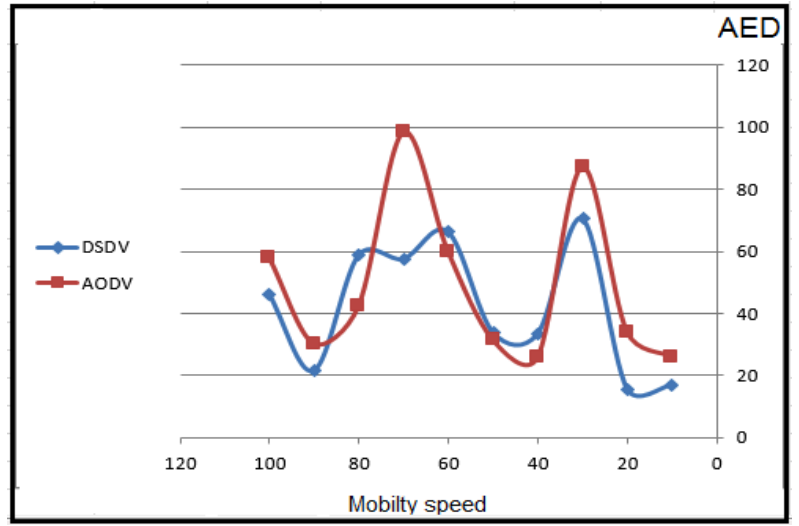

Figure 7: AED versus mobility speed ranging from 10 to $100 \mathrm{~m} / \mathrm{sec}$

\section{DISCUSSION}

According to the measured values of PDR in figure 2 and 6 , one notes that the PDR remains relatively stable in AODV, this means that the protocol reacts to the disconnection due to the nodes mobility. This reaction minimizes the data loss and thus increases the network reliability. However, the impact of mobility on DSDV is significant and the performance of DSDV decreases drastically when increasing the speed of mobility for mobile nodes. The impact of the speed of mobile nodes on the measured values of AED was unpredictable in both AODV and DSDV as noticed in figures 3 and 7 .

According to measured values of PDR and AED in figures 4, and 5 respectively which are based on keeping the speed of mobile nodes constant at $10 \mathrm{~m} / \mathrm{s}$ and varying the number of connections from 5 to 20 , one can note that the variation of PDR is stable in AODV. This note indicates that the loss of data is minimal in spite of the great number of connections. The result in DSDV show low number of PDR with low number of connections and it is become stable with high number of connections. AODV present end to end delay low number of end-to-end delay with low number of connections and it is become stable with high number of connections and increase the delay as number of connections is increased.

\section{CONCLUSION}

This simulation based study was conducted to evaluate the performance of the MANET protocols AODV and DSDV. These routing protocols were compared in terms of Packet delivery ratio and Average end-to-end delay. Simulations have shown that performance of a routing protocol varies widely across different performance differentials. It is observed AODV perform better in simulations than DSDV. To conclude, AODV outperforms DSDV in Ad-hoc networking environments, so AODV could be used as a base protocol when we talk of developing a new protocol for Adhoc networks and the future research must be focused on improving and implementing the new protocol in Ad-hoc networks.

\section{FUTURE WORK}

This paper is a preliminary study of such type of wireless communication network, Ad hoc Networks. Although, Ad hoc networking is not a new concept, it is a dynamic field and still being under investigation and development due to the emergence of new technologies such as the Bluetooth, IEEE 802.11 and Hyperlan which are helping in enabling eventual commercial MANET deployments outside the military domain. So, this study will be extended by considering different applications of ad hoc networking such as MANET and Vehicular Ad hoc network (VANET). Synthetic and real mobility models will be used to held a fair comparison between different categories of routing protocols.

\section{ACKNOWLEDGMENTS}

I would like to thank both of Dr. Ghada Elnifie who put the corner stone of this work and my students including Albatool Ali Asiry, Njoud Abdullah Alshehri, Rawan Abdullah Alkraan, Sumayah Mohammad Alshoqyran who have implemented the simulation experiments under my supervision as a supplement for their graduation project.

\section{REFERENCES}

[1] Pravin, G., Girish, K., and Pradip, G., Mobile Ad Hoc Networking: Imperatives and Challenges, IJCA Special issue on MANETs, 2010.

[2] I.Vijaya, P. B. Mishra, Influence of Routing Protocols in Performance of Wireless Mobile Adhoc Network, 978-07695-4329-1/11, Second International Conference on Emerging Applications of Information Technology, IEEE, 2011.

[3] H. Zhou, A Survey on Routing Protocols in MANETs, Technical Report MI 48824-1027, MSUCSE , 2003.

[4] C. Perkins, E. Belding-Royer, and S. Das, Ad hoc OnDemand Distance Vector (AODV) Routing, RFC 3561, 2003.

[5] Perkins .C. E and Bhagwat P.,Highly Dynamic Destination-Sequenced Distance-Vector Routing (DSDV) for Mobile Computers. Comp, 1994.

[6] Ford Jr. L. R. and Fulkerson. D. R., Flows in Networks, Princeton Univ. Press, 1962.

[7] NITISH P., NEELAM SH., MOBILE AD-HOC NETWORK: OPTIMIZATION OF ROUTING ALGORITHMS FOR MOBILITY MODEL, IJRIC, 2076-3328,2011.

[8] Jacobson V., LBL, Braden R., ISI, Borman D., Cray Researsh, TCP extensions for High Performance, ITEF RFC 1323, May 1992.

[9] V. SAMESWARI, DR.E.RAMARAJ, A Study of TableDriven and On-Demand Routing Protocols in MANET, Vol 5 (2),522-529, IJCTA,2014

[10] I.Vijaya, Pinak Bhusan Mishra, Influence of Routing Protocols in Performance of Wireless Mobile Adhoc Network, Second International Conference on Emerging Applications of Information Technology, 2011.

[11] Corson, J. Macker (January1999). " Routing Protocol Performance Issues and Evaluation considerations" RFC 2501, IETF Network Working Group, January1999. http://www.ietf.org/rfc/rfc2501.txt cited 15.02.2004. 